\title{
Decompression of a pneumoperitoneum during an extraperitoneal inguinal hernia repair (TEP) by incision of the umbilical sac under direct vision
}

\author{
T. Sinnett $\cdot$ N. Karanjia
}

Received: 26 September 2009 / Accepted: 23 November 2009 / Published online: 10 December 2009

(C) Springer-Verlag 2009

\section{Background}

Peritoneal tears are a recognised complication of extraperitoneal inguinal hernia repair (TEP) [1] and can necessitate conversion to transabdominal pre-peritoneal (TAPP) repair due to loss of the extraperitoneal space. To avoid this conversion, which carries with it risks of further complications [2], it is possible to decompress the pneumoperitoneum and complete the TEP repair. This decompression can be performed with a Verres needle at Palmer's point; however, this decompression is slow, rarely provides a complete decompression and carries the risk of further complications [3].

\section{Technique}

When performing a TEP repair of an inguinal hernia using a direct trocar insertion technique below the umbilicus, in the event of creating a pneumoperitoneum due to a peritoneal tear it is possible to incise the umbilical sac under direct vision and thus decompress the pneumoperitoneum and continue with the procedure. This defect can then be closed with a suture at the end of the procedure.

\section{Discussion}

The possibility of decompressing the pneumoperitoneum with this technique was made apparent at the time of performing a TEP repair of an inguinal hernia on a patient who had a concurrent umbilical hernia. However, the presence of such a hernia is not a pre-requisite for this method of decompression. The TEP was completed without the need to convert to TAPP. This method can be performed safely whenever a TEP is complicated by a pneumoperitoneum.

\section{References}

1. Lau H, Patil NG, Yuen WK, Lee F (2002) Management of peritoneal tear during endoscopic extraperitoneal inguinal hernioplasty [see comment]. Surg Endosc 16(10):1474-1477

2. Lovisetto F, Zonta S, Rota E, Bottero L, Faillace G, Turra G, Fantini A, Longoni M (2007) Laparoscopic Transabdominal Preperitoneal (TAPP) hernia repair: surgical phases and complications. Surg Endosc 21(4):646-652

3. Byron JW, Markenson G, Miyazawa K (1993) A randomized comparison of Verres needle and direct trocar insertion for laparoscopy. Surg Gynecol Obstet 177(3):259-262

T. Sinnett $\cdot$ N. Karanjia

Royal Surrey County Hospital, Guildford, Surrey, UK

T. Sinnett $(\square)$

22 Ballantine Street, Wandsworth London SW18 1 AL, UK

e-mail: tim.sinnett@ic.ac.uk 